\title{
Using Conducting Polymers as Active Agents for Marine Antifouling Paints
}

\author{
Alessandra Fiorini Baldissera ${ }^{a}$, Karine Leite de Miranda ${ }^{a}$, Christine Bressy ${ }^{b}$, \\ Claire Martin ${ }^{b}$, André Margaillan ${ }^{b}$, Carlos Arthur Ferreira ${ }^{a}$
}

\begin{abstract}
${ }^{a}$ Laboratório de Materiais Poliméricos - LAPOL, Programa de Pós-Graduação em Engenharia de Minas, Metalúrgica e Materiais - PPGE3M, Universidade Federal do Rio Grande do Sul - UFRGS, CP 15010, CEP 91501-970, Porto Alegre, RS, Brazil

${ }^{b}$ Matériaux Polymères Interfaces Environnement Marin - MAPIEM, Institut des Sciences de l'Ingénieur de Toulon et du Var-ISITV, Université du Sud-Toulon - Var, CP 20132, CEP 83957, La Garde, France
\end{abstract}

Received: July 1, 2014; Revised: December 6, 2015

\begin{abstract}
Antifouling coatings were prepared with paints containing polyaniline (PAni) and derivatives as active pigment, and evaluated by antifouling performance on metallic or polyvinyl chloride substrates. The paints, PAni and its derivatives were characterized by FT-IR spectrophotometry, thermogravimetric analysis, electrical conductivity and scanning electron microscopy. Coatings were also characterized by salt spray, leaching and erosion tests. Antifouling coatings' performance was evaluated by immersion tests in a marine environment or in fresh water. Paints containing PAni-ES, PAni/DBSA and SPAN, and a co-biocide PyZn, showed antifouling performance similar to a commercial antifouling paint.
\end{abstract}

Keywords: conducting polymer, polyaniline, epoxy, coating, antifouling

\section{Introduction}

When at sea for any length of time, ships' hulls are subject to attack by fouling organisms, such as barnacles, mussels and algae, resulting in a significant reduction in operating efficiency, with a consequent increase in costs owing to the increase in fuel consumption. An organism incrustation in the order of $10 \mu \mathrm{m}$ may mean an increase of 0.3 to $1 \%$ in fuel consumption ${ }^{1}$.

Among all the solutions proposed since early navigation history, it is universally recognized that prevention can be achieved by the use of marine coatings containing toxic molecules, named biocides ${ }^{2}$. Thus, self-polishing paints containing TBT (tributyl tin) were the most successful coating system in combating biofouling on ships ${ }^{3-5}$. However, its widespread use has caused severe pollution in the marine ecosystem, and in January 2003, several countries banned the manufacture of antifouling paints using these active molecules, and from January 2008, also banned its presence in surface coating vessels ${ }^{2,6}$. It is therefore urgent to choose other antifouling additives that could be effective, but not harmful to the environment.

TBT-free formulations, in which tin is replaced by metals like copper ${ }^{7,8}$, zinc ${ }^{9}$ and titanium ${ }^{10}$, are in use today. Although copper is essential for all forms of life due to cellular processes, it is considered toxic when tolerance limits are exceeded ${ }^{7}$. Copper has excellent antifouling properties against barnacles and algae, even though some species are resistant to this metal. Together with copper, other toxic biocides such as copper thiocyanate, zinc pyrithione, Diuron $^{\circledR}$ (3-(3',4'-dichlorophenyl)-1,1-dimethylurea) and

*e-mail: alebaldissera@hotmail.com
Irgarol $^{\circledR} 1051$ (2-(tert-butylamino)-4- cyclopropylamino)6-(methylthio)-1,3,5-triazine) are used to increase the efficiency of antifouling coatings ${ }^{11}$.

For some years, the materials known as electric conducting polymers have been employed in the manufacture of protective coatings, against corrosion of metals in two forms: doped and undoped ${ }^{12-17}$. These polymers, when doped and conducting, are able to protect steel against corrosion by an anodic protection mechanism, owing to the formation of an iron mixed oxide layer of high protection capacity, as well as being able, in the case of a coating fracture, to regenerate the metal oxide layer. It was reported that, besides the ability to protect metals against corrosion, these polymers also have potential for use as additives in antifouling paints ${ }^{18}$. Paints containing cuprous oxide and polyaniline (PAni), or its sulphonated derivative (SPAN), showed a much more effective antifouling protection than paint containing only cuprous oxide, suggesting a synergistic effect between these two compounds.

The main objectives of this study were to produce a class of non-conventional paints containing conductive polymers as an active antifouling pigment, to characterize and to test the products by in situ immersion to assess the performance of coatings against marine fouling. Samples of paint containing PAni doped with $\mathrm{HCl}$, in combination with the co-biocide zinc pyrithione (PyZn) in the formulation immersed in sea water, were effective against marine fouling over more than twelve months; longer than the period used by commercial paint as a reference. These results led the authors to the application for a patent ${ }^{19}$. 


\section{Experimental}

\subsection{Preparation of PAni; undoping; doping with dodecylbenzenesulphonic acid (DBSA) and sulphonation}

PAni-ES (PAni doped with $\mathrm{HCl}$ ) was prepared according to the procedure described by MacDiarmid ${ }^{20}$. Typically, polymerization reaction of aniline was carried out at temperatures between -4 and $0{ }^{\circ} \mathrm{C}$, for $8 \mathrm{~h}$. A solution consisting of an oxidizing agent $\left[\left(\mathrm{NH}_{4}\right)_{2} \mathrm{~S}_{2} \mathrm{O}_{8}\right]$ in $1 \mathrm{M} \mathrm{HCl}$ was added slowly with constant agitation, to a $1 \mathrm{M} \mathrm{HCl}$ solution containing the monomer. PAni-ES obtained was filtered through porous glass funnel $\# \mathrm{G} 5$, under low pressure to speed up the process. The green powder was washed with distilled water, and finally dried in an oven at $60^{\circ} \mathrm{C}$ for $24 \mathrm{~h}$.

PAni-EB was obtained after treatment of PAni-ES with a 0.1 mol. $\mathrm{L}^{-1} \mathrm{NH}_{4} \mathrm{OH}$ solution in water. After $24 \mathrm{~h}$ under constant stirring, the solution was filtered, and the dark blue powder rinsed with distilled water. The product was dried in an oven at $60^{\circ} \mathrm{C}$ for $24 \mathrm{~h}$.

Doping of PAni-EB was achieved in a 0.16 mol. $\mathrm{L}^{-1}$ aqueous solution of a commercial DBSA, NACURE 5076 (Kings Industries Ltd, GB), maintained at $40{ }^{\circ} \mathrm{C}$ under vigorous stirring for $24 \mathrm{~h}$. PAni/DBSA was rinsed with distilled water and cold acetone $\left(\mathrm{T}=5^{\circ} \mathrm{C}\right)$. The polymer was dried in an oven at $60^{\circ} \mathrm{C}$ for $24 \mathrm{~h}$.

To obtain SPAN, 10g of PAni-ES was dispersed in $300 \mathrm{~mL}$ of 1.2-dichloroethane (DCE). Chlorosulphonic acid $\left(\mathrm{HSO}_{3} \mathrm{Cl}\right)$ was diluted to $1.5 \mathrm{M}$ with DCE, and dripped slowly into the PAni dispersion heated to $80^{\circ} \mathrm{C}$. The reaction was stirred for $5 \mathrm{~h}$ under reflux. The chlorosulphonated polyaniline was filtered and dispersed in water, heated to $100{ }^{\circ} \mathrm{C}$, and maintained at this temperature for another $4 \mathrm{~h}$ to promote hydrolysis. Finally, the product was precipitated in acetone, filtered and dried in an oven at $60^{\circ} \mathrm{C}$ for $24 \mathrm{~h}$.

\subsection{Preparation of paints}

Paints were prepared according to the procedure described by Baldissera ${ }^{21}$. The components were weighed as a basic formulation described in Table 1. The pigments and charge were completely dispersed in the resin (epoxy monocomponent or bicomponent) and additives, using a DISPERMAT N1 disperser, during $30 \mathrm{~min}$. After this time, zirconium beads were added to the mix and pigments were ground to achieve optimum dispersion. The particle size of dispersion, evaluated using a Fineness of Grind Gauge, was between 6 and 7 Hegman ( 25 and $15 \mu \mathrm{m}$ ). Finally, resin and solvent were added to achieve the desired viscosity.

\subsection{Preparation of samples}

Table 2 describes the nomenclature of the thirteen paints prepared, that differ in the nature of epoxy resin used, as well as the amount and type of pigments used.

Steel plates SAE 1010 , size $(250 \times 200 \times 1) \mathrm{mm}$, were first degreased with xylene, and the paints applied to the substrate using a brush. Samples were then stored in a dust-free place until complete drying of the coating. The coating's thickness was evaluated after evaporation of solvent at room temperature.

PVC plates, size $(200 \times 150 \times 8) \mathrm{mm}$, were first worn by the abrasive process and degreased with water and detergent, and then with ethanol. The different formulations were also applied to the substrate using a brush.

\subsection{Instruments}

Characterization of the polymers was carried out by FTIR analysis and electrical conductivity, using the standard method of four points ${ }^{22}$.

Adhesion of the coatings to the metal substrate was evaluated in accordance with ASTM D3359-9723. The thickness of each coating was measured at eight different locations on the surface, using a Byko-test 7500 thickness meter. Salt spray tests were carried out in a mist chamber of $5 \% \mathrm{NaCl}$, as the standard for the following criteria: rusting degree (ISO 4628-3) 24 $^{24}$, blistering degree (ASTM D714-02) ${ }^{25}$ and subcutaneous migration (NBR MB787-74) ${ }^{26}$.

Plates coated with different formulations were submerged in the sea (TRANSPETRO, Petrobrás Transporte S.A), between Tramandaí river and Imbé beach, RS/Brazil (geographical position $29^{\circ} 58^{\prime} 35.5^{\prime \prime} \mathrm{S}, 50^{\circ} 07^{\prime} 23.0^{\prime \prime} \mathrm{W}$ ), to assess the marine fouling organisms. The salinity at this site was approximately $2.5 \%$. Antifouling paints were also evaluated in Mediterranean Sea, with plates immersed at Arsenal du Mourillon, Toulon, France (geographical position $\left.43^{\circ} 06^{\prime} 24.7^{\prime \prime} \mathrm{N}, 5^{\circ} 56^{\prime} 19.6^{\prime \prime} \mathrm{E}\right)$. The salinity at this site was approximately $3.5 \%$ salinity.

A leaching test was carried out in a Jar Test Microcontroller equipment at a speed of $60 \mathrm{rpm}$ (ASTM D6442-05) ${ }^{27}$. Samples were prepared by applying the paint on epoxy resin plates $(75 \times 110) \mathrm{mm}$, using a brush. After complete drying of the coatings, plates were immersed in $3.5 \% \mathrm{NaCl}$. Aliquots of this solution were evaluated by an atomic absorption spectrophotometer.

Table 1. Paints composition.

\begin{tabular}{|c|c|c|}
\hline Component & Formulation without PAni (\%) & Formulation with PAni (\%) \\
\hline Epoxy resin $^{(a)}$ & 27.7 & 25.1 \\
\hline Pigments $\left(\mathrm{Cu}_{2} \mathrm{O}+\mathrm{TiO}_{2}^{(\mathrm{b})}\right)$ & 47.9 & 34.7 \\
\hline PAni & - & 8.7 \\
\hline Charge & 5.4 & 5.0 \\
\hline Solvent ${ }^{(\mathrm{c})}$ & 13.9 & 20.1 \\
\hline Additives process & 5.1 & 6.4 \\
\hline
\end{tabular}

(a) Bicomponent or monocomponet. ${ }^{(b)} \mathrm{Cu}_{2} \mathrm{O}$ - cuprous oxide; $\mathrm{TiO}_{2}$ - titanium dioxide. ${ }^{(\mathrm{c})}$ Initial amount of solvent used to make the dispersion and grinding of pigments. 
The coatings obtained were evaluated further for thermal stability (Thermogravimetric Analyser) and surface morphology, by scanning electron microscopy.

\section{Results and Discussion}

\subsection{Electrical conductivity}

Electrical conductivity was measured by a four-point

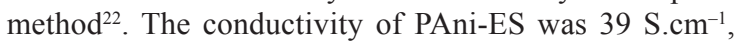
PAni/DBSA was $0.3 \mathrm{~S} . \mathrm{cm}^{-1}$ and SPAN was $1.4 \mathrm{~S} . \mathrm{cm}^{-1}$. It was not possible to measure PAni-EB conductivity, as well as the conductivity of all the coatings' films, because their conductivity was too low to be measured adequately. This could be attributed to the other components present into the films as pigments and fillers, which are electrical insulators and contributed to the low conductivity of the samples.

Generally, the smaller the size of the acid chain - thus diffusing easily into the conducting polymer chain - more effective the doping process, and this may explain the conductivity values presented by PAni-ES compared with PAni/DBSA.

\subsection{FTIR analysis}

The polymers used as pigments were subjected to analysis by infrared spectroscopy. Figure 1 shows the infrared spectra for PAni-EB, PAni-ES, PAni/DBSA and SPAN.

PAni-EB spectrum shows two strong absorption bands at $1586 \mathrm{~cm}^{-1}$ and $1495 \mathrm{~cm}^{-1}$, attributed to the $\mathrm{C}=\mathrm{C}$ bonds strength of aromatic ring groups quinols (Q) and benzenoid (B) respectively. In the PAni-ES and PAni/DBSA spectra these bands move to regions of lower wavenumber (1560 and $1475 \mathrm{~cm}^{-1}$ and 1557 and $1479 \mathrm{~cm}^{-1}$, respectively), owing to the creation of positive charges on the polymer chain showing a characteristic behaviour of doped polymer. These values are similar to those reported previously by the authors in another study also using conductive polymers ${ }^{28}$. The band present in the PAni-EB spectrum at $1376 \mathrm{~cm}^{-1}$, related to the C-N stretch of units QBQ, disappears completely in the PAni-ES and PAni/DBSA spectra, revealing that the doping process with the polaron formation $\left(\mathrm{C}-\mathrm{N}^{+}\right)$was very effective. The bands at $1030 \mathrm{~cm}^{-1}$ and $1004 \mathrm{~cm}^{-1}$ that are present only in the PAni/DBSA spectrum are assigned to $\mathrm{S}=\mathrm{O}$ bonds of the sulphonic acid used as dopant. In the SPAN spectrum, we

Table 2. Paints nomenclature obtained in the laboratory.

\begin{tabular}{|c|c|c|}
\hline Paint & Epoxy resin & Pigments \\
\hline T1-EB & Bicomponent & $\mathrm{Cu}_{2} \mathrm{O} ; \mathrm{TiO}_{2}$ \\
\hline T1-EBPy & Bicomponent & $\mathrm{Cu}_{2} \mathrm{O} ; \mathrm{TiO}_{2} ; \mathrm{PyZn} *$ \\
\hline T1-EM & Monocomponent & $\mathrm{Cu}_{2} \mathrm{O} ; \mathrm{TiO}_{2}$ \\
\hline T1-EMPy & Monocomponent & $\mathrm{Cu}_{2} \mathrm{O} ; \mathrm{TiO}_{2} ; \mathrm{PyZn} *$ \\
\hline T2-EMPAniEB & Monocomponent & $\mathrm{Cu}_{2} \mathrm{O} ; \mathrm{TiO}_{2} ;$ PAni-EB \\
\hline T2-EMPAniEBPy & Monocomponent & $\mathrm{Cu}_{2} \mathrm{O} ; \mathrm{TiO}_{2} ;$ PAni-EB; PyZn* \\
\hline T3-EBPAniES & Bicomponent & $\mathrm{Cu}_{2} \mathrm{O} ; \mathrm{TiO}_{2} ; \mathrm{PAni}-\mathrm{ES}$ \\
\hline T3-EMPAniES & Monocomponent & $\mathrm{Cu}_{2} \mathrm{O} ; \mathrm{TiO}_{2} ; \mathrm{PAni}-\mathrm{ES}$ \\
\hline T3-EMPAniESPy & Monocomponent & $\mathrm{Cu}_{2} \mathrm{O} ; \mathrm{TiO}_{2} ;$ PAni-ES; PyZn* \\
\hline T4-EMPAniDBSA & Monocomponent & $\mathrm{Cu}_{2} \mathrm{O} ; \mathrm{TiO}_{2} ; \mathrm{PAni} / \mathrm{DBSA}$ \\
\hline T4-EMPAniDBSAPy & Monocomponent & $\mathrm{Cu}_{2} \mathrm{O} ; \mathrm{TiO}_{2} ; \mathrm{PAni} / \mathrm{DBSA} ; \mathrm{PyZn} *$ \\
\hline T5-EMSPAN & Monocomponent & $\mathrm{Cu}_{2} \mathrm{O} ; \mathrm{TiO}_{2} ; \mathrm{SPAN}$ \\
\hline T5-EMSPANPy & Monocomponent & $\mathrm{Cu}_{2} \mathrm{O} ; \mathrm{TiO}_{2} ; \mathrm{SPAN} ; \mathrm{PyZn} *$ \\
\hline
\end{tabular}

*The amount of PyZn (zinc pyrithione) used in the formulations was 5\%, calculated on the total weight of the formulation.

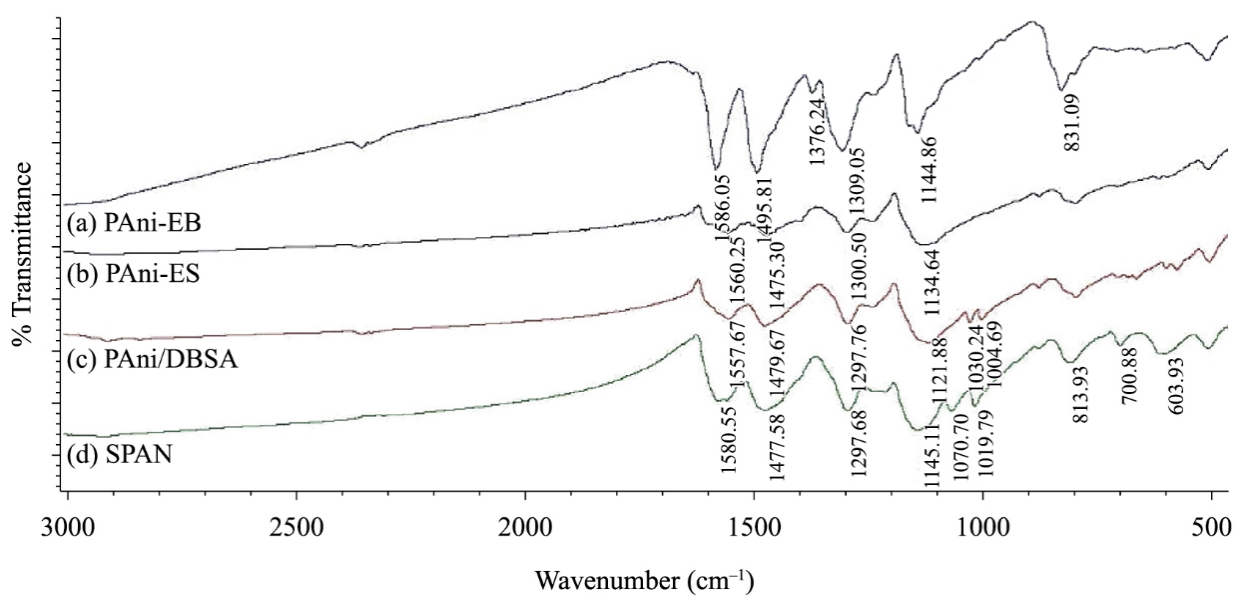

Figure 1. FTIR spectra of (a) PAni-EB; (b) PAni-ES; (c) PAni/DBSA; (d) SPAN. 
can observe the bands at $1580 \mathrm{~cm}^{-1}$ and $1477 \mathrm{~cm}^{-1}$ assigned to the $\mathrm{C}=\mathrm{C}$ bonds stretching of the aromatic groups quinols (Q) and benzenoid (B). The bands at $1070 \mathrm{~cm}^{-1}$ and $1019 \mathrm{~cm}^{-1}$ are assigned to asymmetric and symmetric deformation of the $\mathrm{S}=\mathrm{O}$ bond, respectively. The band at $813 \mathrm{~cm}^{-1}$ shows the outside plane deformation the ring tri-substituted 1, 2 and 4. The bands at $700 \mathrm{~cm}^{-1}$ and $603 \mathrm{~cm}^{-1}$ are assigned to the $\mathrm{S}-\mathrm{O}$ and C-S bonds, respectively.

\subsection{Adherence test}

The adhesion of the primer, antifouling samples and commercial paint used in the work for comparison have been determined. All steel plates received a layer of primer and two layers of antifouling paint. Analysis of the results was performed according to classification described in ASTM D3359-9723 and is presented in Table 3.

It was observed that coatings obtained from paints prepared in the laboratory showed better adhesion than coating obtained with the commercial paint, with exception of sample T4-EMPAniDBSAPy (paint containing PAni/DBSA and PyZn), whose classification was $0 \mathrm{~B}$; i.e., more than $65 \%$ of the film was removed. This low adherence may be related to the nature and amount of surfactant (DBSA) used to dope the PAni, since the sample T4-EMPAniDBSA also showed less adherence than other samples prepared in the laboratory. The primer presented a classification $5 \mathrm{~B}$, which means no coating was removed, indicating that coating adhesion to the metal substrate was excellent.

Samples coated with paints obtained with the bicomponent epoxy resin (T1-EB, T1-EBPy and T3-EBPAniES) not been evaluated in this test since it doesn't show good results on immersion tests, i.e., antifouling performance analysis.

Table 3. Adhesion test classification of the coatings.

\begin{tabular}{cc}
\hline Sample & Classification* \\
\hline T1-EM & $3 \mathrm{~B}$ \\
T1-EMPy & $4 \mathrm{~B}$ \\
T2-EMPAniEB & $4 \mathrm{~B}$ \\
T2-EMPAniEBPy & $4 \mathrm{~B}$ \\
T3-EMPAniES & $4 \mathrm{~B}$ \\
T3-EMPAniESPy & $5 \mathrm{~B}$ \\
T4-EMPAniDBSA & $1 \mathrm{~B}$ \\
T4-EMPAniDBSAPy & $0 \mathrm{~B}$ \\
T5-EMSPAN & $4 \mathrm{~B}$ \\
T5-EMSPANPy & $4 \mathrm{~B}$ \\
Commercial & $1 \mathrm{~B}$ \\
Primer & $5 \mathrm{~B}$ \\
\hline
\end{tabular}

$* 5 \mathrm{~B}-0 \%$ area removed; $0 \mathrm{~B}-$ more than $65 \%$ of area removed

\subsection{Salt spray testing}

Salt spray testing was performed with paints T1-EB and T1-EM, to evaluate the performance of the resin used against corrosion. For each paint, three samples were prepared. The results followed the standards for each criterion, and the averages obtained from the samples are presented in Table 4.

It was observed that performance of the bicomponent epoxy resin (T1-EB) was excellent, with small bubbles only after $672 \mathrm{~h}$ testing. After $1536 \mathrm{~h}$ the test was interrupted and the rusting degree and subcutaneous migration of samples were zero. On the other hand, performance of the monocomponent epoxy resin (T1-EM) was not as good as the paint T1-EB, already showing changes in the coating after $96 \mathrm{~h}$ of testing. After approximately $400 \mathrm{~h}$ of testing, some parts of the coating loosened from the plates, thus resulting in points of rusting in unprotected areas. After $672 \mathrm{~h}$ of testing, samples already had many bubbles in the parts still covered with paint. It was observed that despite the size and density of the bubbles being high grade (T4, D4), the surface still protected by the coating did not present any degree of rusting.

\subsection{Antifouling performance analysis of coatings}

\subsubsection{Test in the Tramandaí river water (Imbé, RS,} Brazil)

Table 5 shows the system and dry film thickness of the antifouling paint used. All tests were done in duplicate.

Primer was used in all the steel plates for the purpose of protection against corrosion. The mean thickness of the films was $30.3 \pm 3.0 \mu \mathrm{m}$. Plate 1 was used as white, since it had not received antifouling paint. Plate 2 was coated with commercial paint and used as a reference. The plates were fixed in two structures built from PVC tubes and dipped into the Tramandaí river water. Figure 2 shows the performance of coatings used on these plates.

After only two weeks of immersion, a lot of Balanus $^{6}$ or barnacles were observed attached to the surface of the white plate. From the sixth week of immersion the growth of these organisms increased, covering the whole coated surface.

Plate coated with commercial paint was efficient for about 45 weeks of immersion. After nine weeks of immersion, it was possible to see small points of primer on the plate; the occurrence of these points increasing with time. These points appeared because the commercial paint is a soluble matrix type, eroding faster and always renewing the active surface of the coating. After 53 weeks of immersion, although there were some points of corrosion, there was adherence of Balanus on all coating.

Figure 3 shows the plates coated with paints prepared with the bicomponent epoxy resin.

Table 4. Results of salt spray testing for coatings.

\begin{tabular}{cccccc}
\hline \multirow{2}{*}{ Paint } & Dry Film thickness $(\boldsymbol{\mu m})$ & \multicolumn{3}{c}{ Time test $(\mathbf{h})$} & \multirow{2}{*}{$\begin{array}{c}\text { Subcutaneous } \\
\text { migration }\end{array}$} \\
\cline { 3 - 5 } & & $\mathbf{1 6 8}$ & $\mathbf{6 7 2}$ & $\mathbf{1 5 3 6}$ & Zero \\
T1-EB & $151.1 \pm 1.3$ & $* \mathrm{~F} 0, \mathrm{~T} 0, \mathrm{D} 0$ & $* \mathrm{~F} 0, \mathrm{~T} 2, \mathrm{D} 2$ & *F0, T4,D3 & - \\
$\mathrm{T} 1-\mathrm{EM}$ & $136.3 \pm 1.5$ & *F0, T4, D4 & $* \mathrm{~F} 3, \mathrm{~T} 4, \mathrm{D} 4$ & - & \\
\hline
\end{tabular}

*F - rusting degree (F0 to F5); $\mathrm{T}$ and D - size and density of bubbles (degree T0 to T5; D0 to D5). Results quality decreases from 0 (excellent) to 5 (very bad). 
Plates coated with paints T1-EB and T1-EBPy showed the Balanus incrustation in the fourth week of immersion. The addition of PyZn in the formulation did not affect the performance of the coating against marine fouling organisms.

Table 5. Paints used in steel plates and dry film thickness of antifouling paint.

\begin{tabular}{ccc}
\hline Plate & Paint & Coating thickness $(\boldsymbol{\mu m})$ \\
\hline 1 & Primer & - \\
2 & Commercial & $30.3 \pm 1.0$ \\
3 & T1-EB & $142.7 \pm 0.5$ \\
4 & T1-EBPy & $171.5 \pm 1.0$ \\
5 & T3-EBPAniES & $55.8 \pm 1.5$ \\
6 & T1-EM & $63.6 \pm 2.2$ \\
7 & T1-EMPy & $35.1 \pm 2.5$ \\
8 & T2-EMPAniEB & $55.1 \pm 1.0$ \\
9 & T2-EMPAniEBPy & $70.3 \pm 2.3$ \\
10 & T3-EMPAniES & $46.8 \pm 2.0$ \\
11 & T3-EMPAniESPy & $50.0 \pm 1.3$ \\
12 & T4-EMPAniDBSA & $52.9 \pm 2.5$ \\
13 & T4-EMPAniDBSAPy & $57.4 \pm 1.5$ \\
14 & T5-EMSPAN & $60.3 \pm 2.5$ \\
15 & T5-EMSPANPy &
\end{tabular}

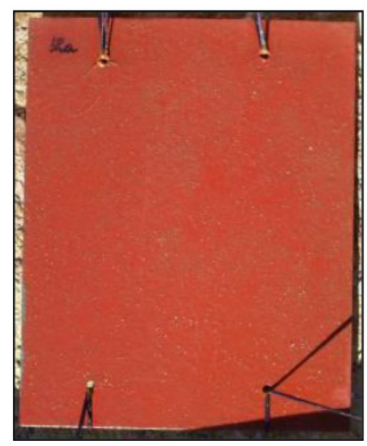

Primer:

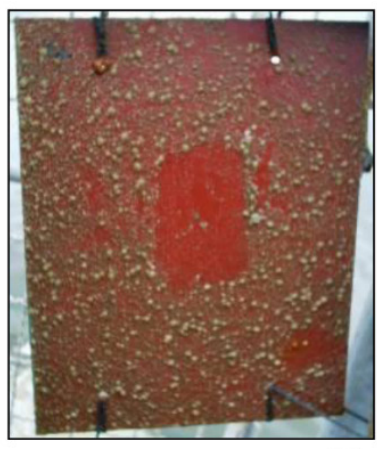

$6^{\text {th }}$
Plate coated with paint T3-EBPAniES showed Balanus incrustation in the third week of immersion, increasing over the course of the weeks.

Owing to the poor performance of paints prepared with the bicomponent epoxy resin against marine fouling organisms, a monocomponent epoxy resin was chosen for the development of the formulations. This resin was chosen because it does not need a reticulation agent, which presents a basic character, and is an unwanted factor that can provoke undoping of the conductive polymer, and cause it to lose its main characteristic that is the electrical conductivity. Figure 4 shows the appearance of plates coated with paints prepared with the monocomponent epoxy resin.

For formulations prepared with this resin, the paints that showed better performance were T3-EMPAniESPy and T4-EMPAniDBSAPy, which contained PyZn in the formulation. The coatings were effective during 53 weeks of immersion in marine environment, and were better than commercial paint. For steel plates coated with the paints T5-EMSPAN and T5-EMSPANPy, the antifouling performance was similar to that presented by commercial paint. The delamination of the coating T3-EMPAniESPy is because the sample, after being removed from the water, it was left exposed to sunlight for complete drying of the surface. Due to the heating of the substrate and corrosion

Figure 2. Appearance plates coated with primer and commercial paint, immersed in the marine environment in the weeks.

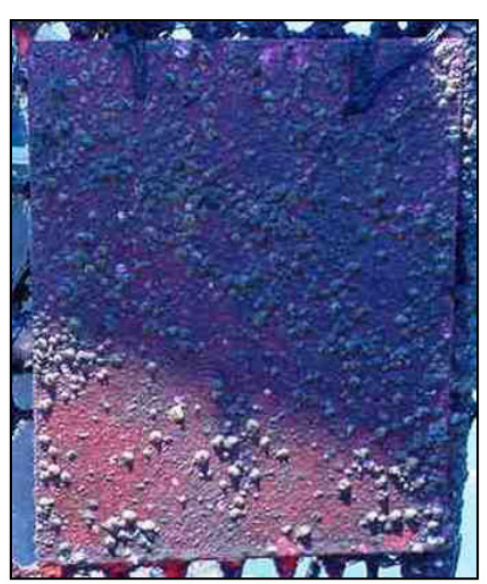

T1-EB:

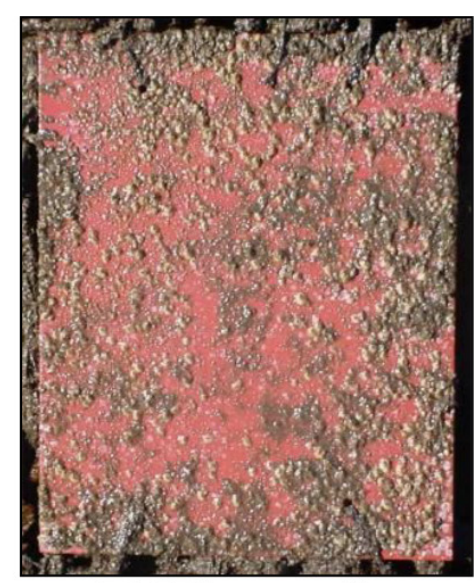

T1-EBPy:

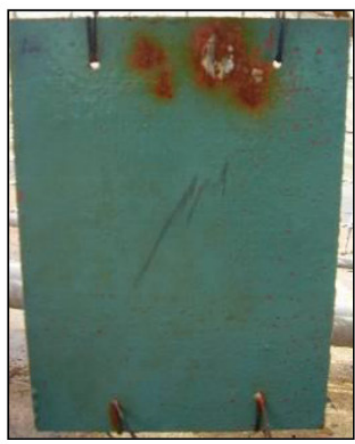

Commercial: $9^{\text {th }}$

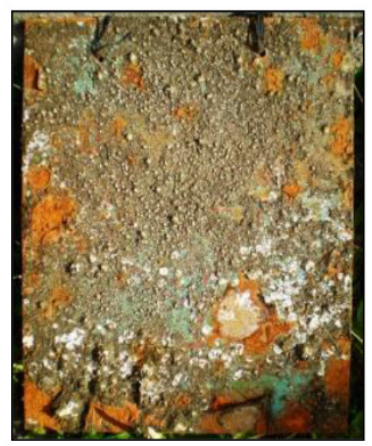

$53^{\text {rd }}$

Figure 3. Appearance of plates coated with paints T1-EB; T1-EBPy and T3-BPAniES and their time of immersion in marine environment. 
subcutaneous present in the sample, the coating suffered a retraction and lifted off from the metal substrate.

By analysing the antifouling performance of coatings obtained with paints formulated with the monocomponent epoxy resin, it was observed that those formulated with PAni in its conductive form (PAni-ES, PAni/DBSA and SPAN) presented an improved antifouling performance. The combination of conductive polymers with PyZn in the formulation makes the coatings as good as, or even better than the commercial paint tested.

Similar results were described by Wang et al. ${ }^{18}$ According to the authors, coatings formed from PAni-ES, with a bicomponent epoxy resin and PAni/DBSA with polyurethane resin, showed a decrease in electrical conductivity after eight weeks of immersion in the sea and also in antifouling efficiency. For the film formed with SPAN and epoxy resin, which had a lower conductivity compared to other films, the conductivity remained relatively stable. Therefore, it is clear that there is a phenomenon of undoping of the conductive polyaniline in the marine environment. It is possible that reaction between copper and polyaniline occurs through the electronic transfer between cuprous ion (I) and conductive polyaniline, favouring the formation of cupric ion (II), which is the active biocide to combat marine fouling. This mechanism is proposed by the following reaction:

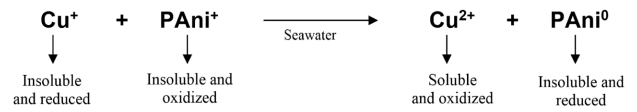

\subsubsection{Test in Mediterranean Sea (Toulon, France)}

PVC plates were used for this test, so it was not necessary to use a coating to provide protection against corrosion. A plate that had not received any coating was used as white, and the plate used as a reference received the commercial self-polishing paint. It was not possible to measure the thickness of coatings obtained, owing to the fact that substrate used was not metal, but two coats of paint were applied to each plate. Plates were trapped in metal structures built for this type of test available in Arsenal du Mourillon, and dipped into the Mediterranean Sea.

The marine organisms that develop and adhere to the surfaces in contact with the water in Mediterranean Sea are different from those observed in southern Brazil. Figure 5

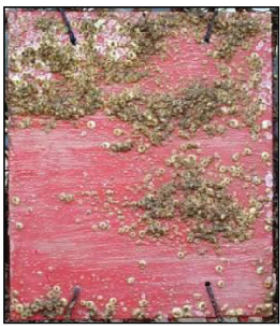

T1-EM: $18^{\text {th }}$

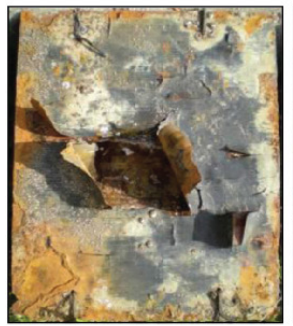

T3-EMPAniESPy: $53^{\text {rd }}$

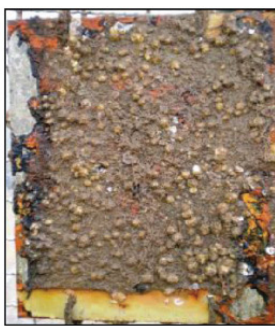

T1-EMPy: $5^{\text {th }}$

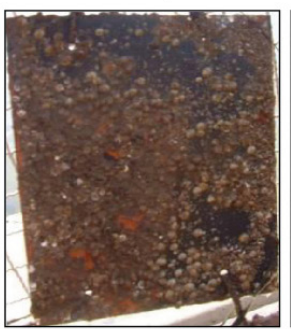

T4-EMPAniDBSA: $41^{\text {st }}$

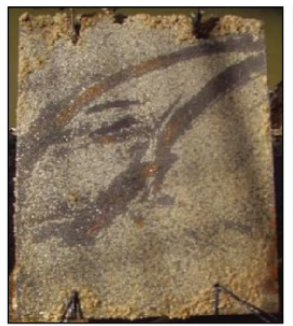

T2-EMPAniEB: $11^{\text {th }}$

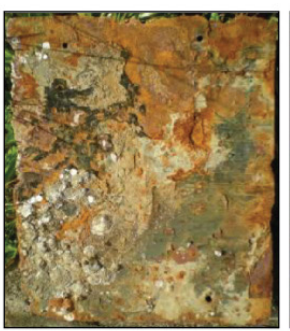

T4-EMPAniDBSAPy: $53^{\text {rd }}$

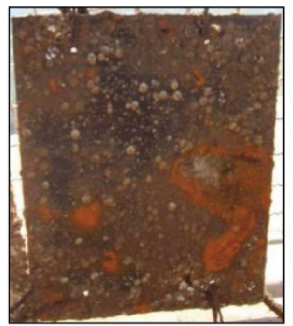

T2-EMPAniEBPy: $41^{\text {st }}$

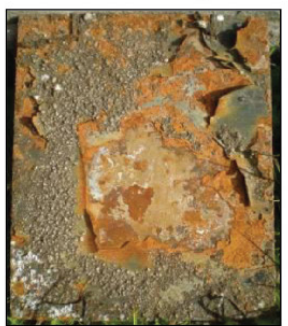

T5-EMSPAN: $53^{\text {rd }}$

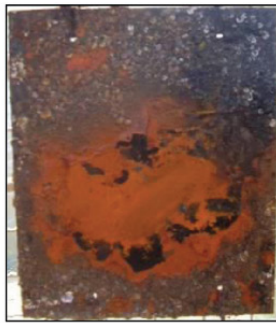

T3-EMPAniES: $41^{\text {si }}$

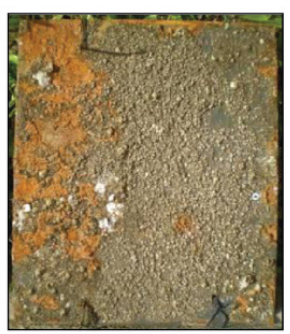

T5-EMSPANPy: $53^{\text {rd }}$

Figure 4. Appearance of steel plates coated with the paints prepared with the monocomponent epoxy resin and its time of immersion in the marine environment (Imbé - Brazil).

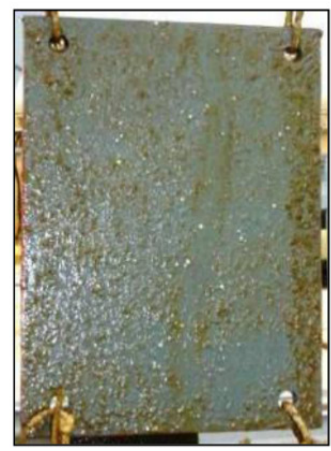

Uncoated: $10^{\text {th }}$

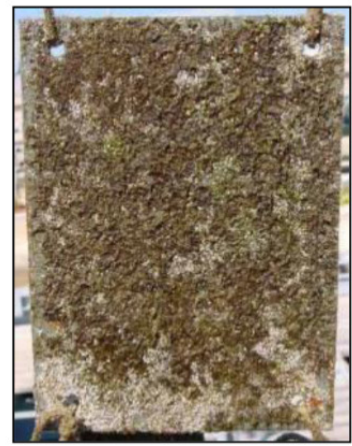

$23^{\text {rd }}$

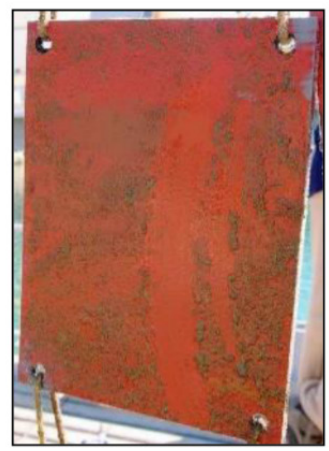

Commercial: $23^{\text {rd }}$

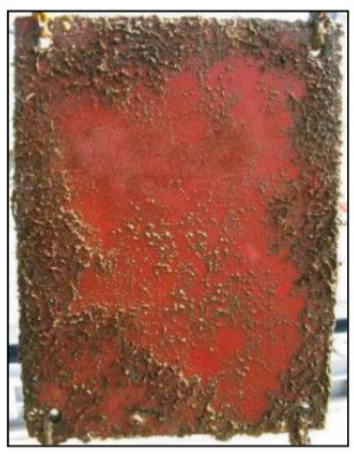

$51^{\text {st }}$

Figure 5. Appearance of plates uncoated and coated with commercial paint and their time of immersion in marine environment. 
shows the plates' appearance, used as white and reference, after adhesion of marine organisms.

A large amount of mud and adhesion of algae was observed on the plate surface used as white after ten weeks of immersion, as well as small white organisms called Spirorbis $^{29}$. After 23 weeks of testing, the plate was completely covered by these organisms. Plate coated with commercial paint showed only a large amount of attached algae on the coating after 23 weeks of immersion. After 51 weeks of immersion, in addition to algae, the adherence of Spirorbis on the coating was observed, which began to develop after 36 weeks of immersion.

Figure 6 shows the performance of some of coatings obtained from paints prepared in the laboratory against marine fouling.

The best antifouling performance was achieved by paint T5-EMSPANPy, which showed only adhesion of algae on the coating, after 51 weeks of testing.

\subsection{Thermogravimetric analysis}

Figure 7 shows the TGA curves obtained for the epoxy resin and paints T1-EM, T4-EMPAniDBSA and T5-EMSPANPy. In the TGA thermogram of epoxy resin, there is a first mass loss between $100^{\circ} \mathrm{C}$ and $300^{\circ} \mathrm{C}$, attributed to moisture loss and entrapped solvent remaining in the sample, which comprises around $25 \%$ of the total. The second event, occurring from $300{ }^{\circ} \mathrm{C}$, is associated with the degradation of the polymer chain.

TGA curves for the three formulations presented in Figure 7 are very similar, because the only difference between samples is the presence of conductive polymer in samples T4-EMPAniDBSA and T5-EMSPANPy. These curves showed a small weight loss at about $70{ }^{\circ} \mathrm{C}$, probably as a result of moisture and loss of residual solvents from the paint-manufacturing process. This event is most visible in the sample T5-EMSPANPy, because the sulphonic group $\left(\mathrm{SO}_{3} \mathrm{H}\right)$ is a strong water absorber.

From TGA curves, the polymer chain degradation temperatures of epoxy resin and conductive polymers ${ }^{30}$ are very close, occurring between around $250{ }^{\circ} \mathrm{C}$ and $750{ }^{\circ} \mathrm{C}$. The very high residue percentage, around $65 \%$, is a result of the large amount of inorganic pigments, fillers and additives used in the paints' formulation (see Table 1).

All formulations showed TGA curves very similar, with the same degradation temperature ranges. The thermogravimetric analysis for these formulations indicates that paints are stable until temperatures below $250^{\circ} \mathrm{C}$, which is the degradation initiation temperature of samples. This temperature is much higher than that required for the type of application and can be applied without restrictions on ships, vessels or structures immersed in marine environment.

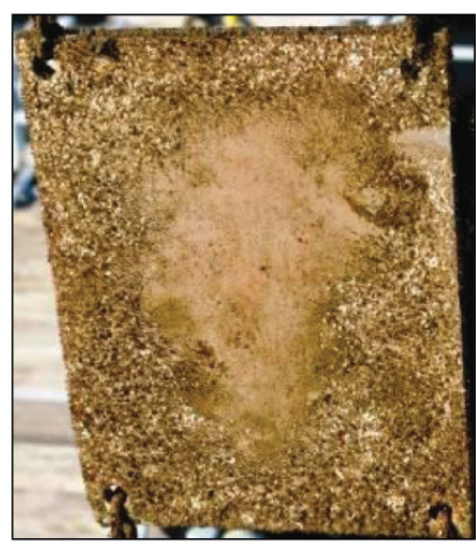

T1-EM: $32^{\text {nd }}$

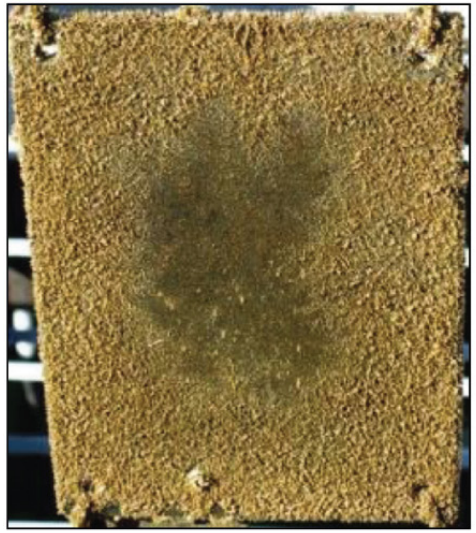

T3-EMPAniESPy: $36^{\text {th }}$

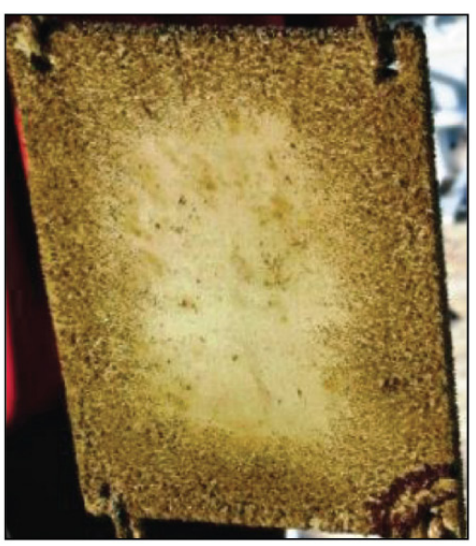

T1-EMPy: $36^{\text {th }}$

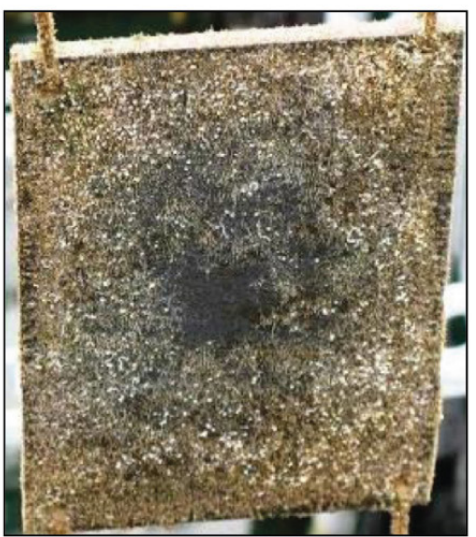

T4-EMPAniDBSA: $36^{\text {th }}$

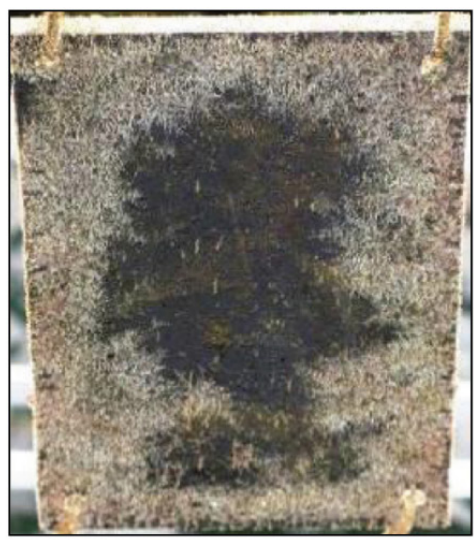

T2-EMPAniEBPy: $32^{\text {nd }}$

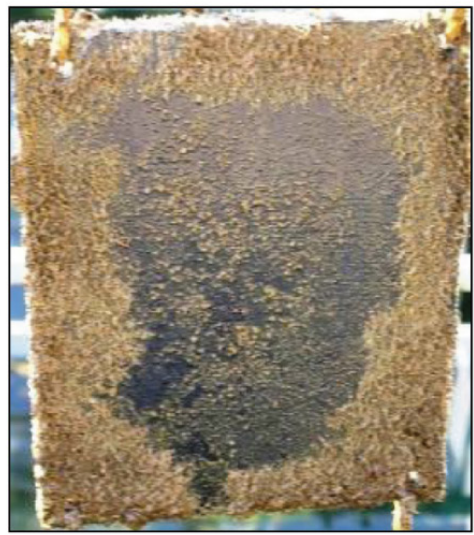

T5-EMSPANPy: $51^{\text {st }}$

Figure 6. Appearance of coated steel plates and their time of immersion in the marine environment (Toulon - France). 


\subsection{Leaching test}

As $\mathrm{Cu}_{2} \mathrm{O}$ is the biocide used in larger amounts in formulations processed in laboratory, it is important to evaluate how it is released from the coating during immersion in water. This process of extraction of the biocide from the polymeric matrix is also known as 'leaching'. There are many parameters that must be taken into account in the study of biocide's release in antifouling paints, such as: biocide and resin nature; charges distribution; interactions between charges/biocide/resin etc. ${ }^{31}$. The graph of the total amount of copper released to the $3.5 \% \mathrm{NaCl}$ aqueous solution versus time is shown in Figure 8.

The copper leaching in most of the coatings is very similar, except for paints T2-EMPAniEBPy and T3-EMPAniESPy. Only after six months of testing, the release of the pigment had grown considerably on the commercial paint.

For most coatings evaluated, the biocide release increases gradually and slowly. After thirty days of testing, a quantity smaller than $1 \mathrm{mg} / \mathrm{L}$ of the biocide was released into the solution. It was observed that for these coatings the presence

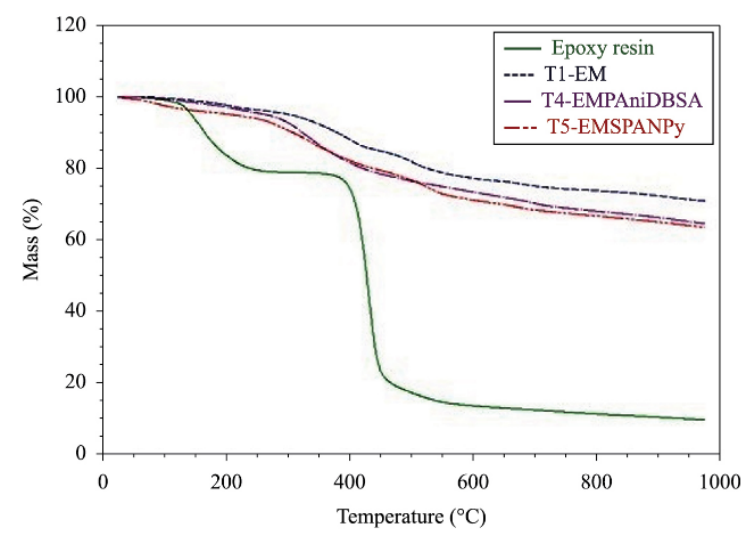

Figure 7. TGA curves of epoxy resin, T1-EM, T4-EMPAniDBSA and T5-EMSPANPy.
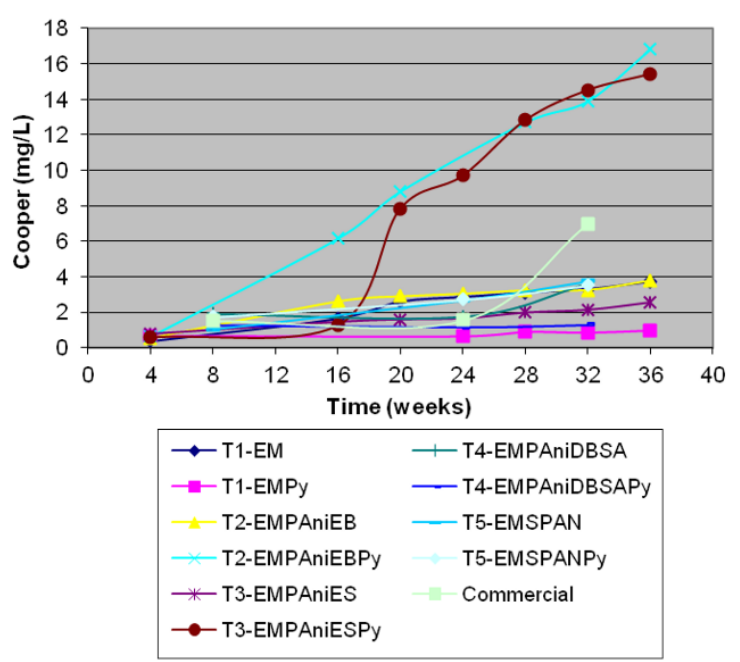

Figure 8. Total concentration of $\mathrm{Cu}$ released in the leaching test. of polyaniline does not modify the process of biocide release through the coating, because after 36-37 weeks of testing, the maximum amount of biocide released to solution was $3.77 \mathrm{mg} / \mathrm{L}$ for paint T2-EMPAniEB; very close to that found for paint T1-EM. Copper leaching is quite different for the coatings obtained from paints T2-EMPAniEBPy and T3-EMPAniESPy. T2-EMPAniEBPy displayed an ascending curve throughout the test duration; the initial amount of copper was $0.62 \mathrm{mg} / \mathrm{L}$ after 4 weeks, and increased to $16.8 \mathrm{mg} / \mathrm{L}$ after 36 weeks of testing. Biocide leaching from paint T3-EMPAniESPy was slow in the first 16 weeks of testing, increasing considerably after this period. The amount of copper released by this coating was 0.59 and $15.4 \mathrm{mg} / \mathrm{L}$, after 4 and 36 weeks of testing, respectively.

As the resin used in the processing was the same for all formulations, the difference in the copper leaching cannot be attributed to it. It was also observed that addition of PAni, or the co-biocide PyZn alone, did not produce significant changes in the results of leaching. However, it is noted that combination of conducting polymer (PAni-EB or PAni-ES) with PyZn increased the copper release significantly, probably owing to the different distribution of pigments and charge at the film, and different interactions between biocide molecules with the conductive polymer, as proposed in the previous reaction.

It is expected that the higher the efficiency of biocide leaching from the coating, the greater efficiency against marine fouling the coating will display. The result obtained in the leaching test for paint T3-EMPAniESPy confirms the test result of immersion in situ, carried out in Brazil. However, it is important to note that leaching test was carried out in $3.5 \% \mathrm{NaCl}$ solution, and in-situ immersion tests were performed in water, with a salinity of about $2.5 \%$; a factor that can change the biocide release to the environment. Compared to the immersion test conducted in France, it was observed that although the paints displayed lower copper leaching, the coating formed from paint T5-EMSPANPy had the best antifouling performance, with only algae adhesion occurring in the 51 weeks of testing.

\subsection{Scanning electron microscopy (SEM)}

In order to verify the pigment distribution in the matrix resin, coating samples were analysed by scanning electron microscopy. Coating morphology was evaluated before and after in-situ immersion test performed in Brazil.

All samples before the immersion test showed similar images. Figure 9 shows the coatings photomicrographs obtained from paints T1-EMPy and T5-EMSPAN. Paint T1-EMPy micrographs (Figure 9a) showed, in addition to $\mathrm{Cu}_{2} \mathrm{O}$ grains and talc lamellae used as filler, grains of $\mathrm{PyZn}$, whose grains are more spherical than $\mathrm{Cu}_{2} \mathrm{O}$ grains and measure about $5 \mu \mathrm{m}$. Micrographs from paint T5-EMSPAN (Figure $9 \mathrm{~b}$ ) showed smaller quantities of $\mathrm{Cu}_{2} \mathrm{O}$ grains and the talc lamellae, larger grains that have been attributed to sulphonated polyaniline. The size of SPAN grains varied between 10 and $15 \mu \mathrm{m}$.

Figure 10 shows the micrographs of coatings formed from paint T1-EMPy and T3-EMPAniESPy, after 53 weeks of immersion in the Tramandaí river (Brazil). In Figure 10a, it is still possible to observe a few grains of biocide distributed 


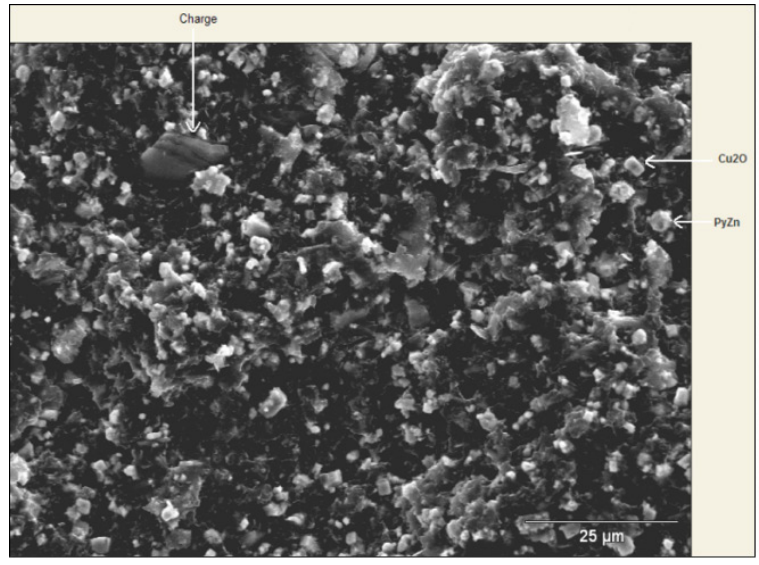

(a)

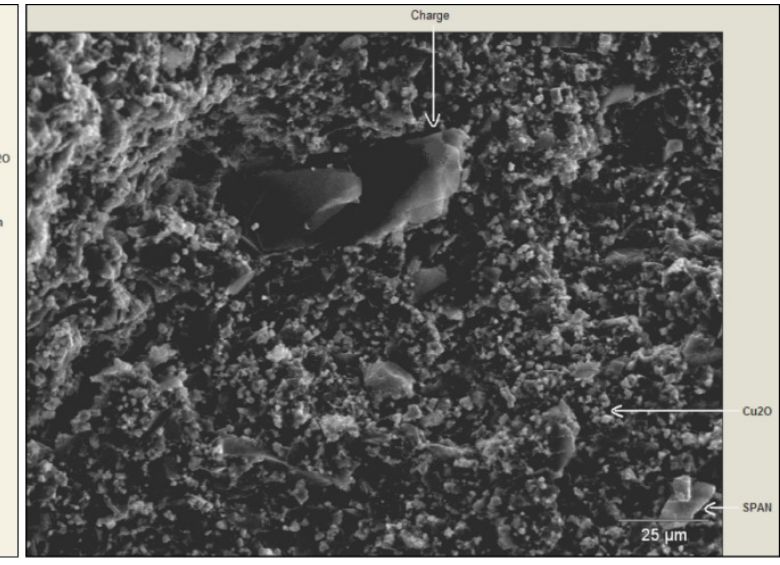

(b)

Figure 9. Micrographs of the coatings (a) T1-EMPy; (b) T5-EMSPAN.

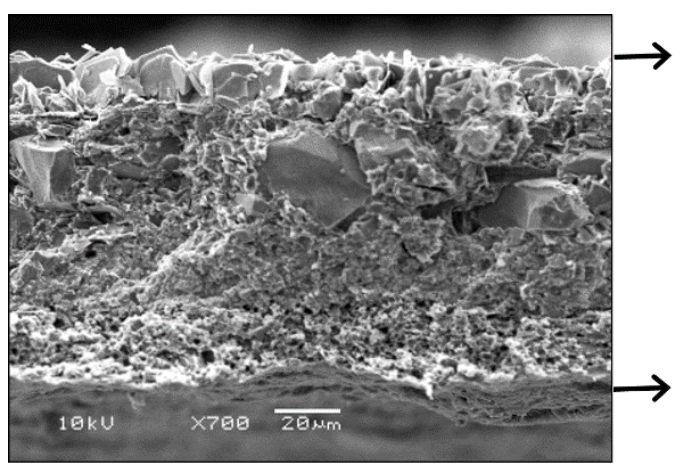

(a)

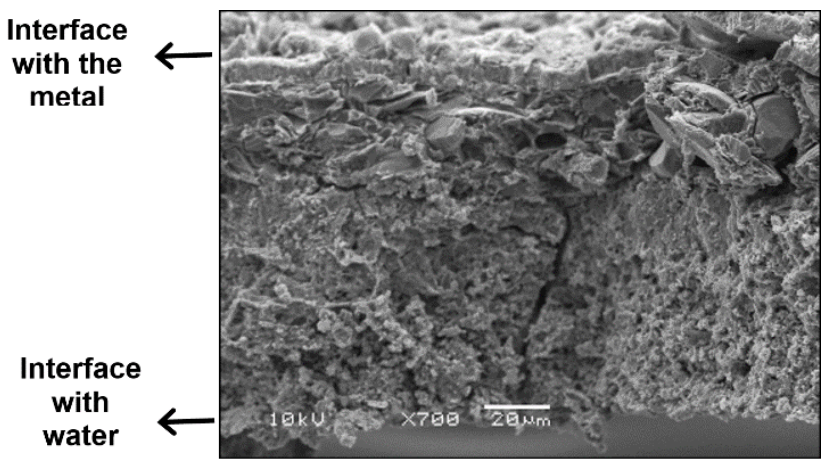

(b)

Figure 10. Micrographs of the coatings (a) T1-EMPy and (b) T3-EMPAniESPy after 53 weeks of immersion.

in the innermost part of the film, next to a thin layer of paint formed by the primer. It is observed that diffusion occurred, facilitating the release of pigments. No particle of biocide $\left(\mathrm{Cu}_{2} \mathrm{O}\right.$ and $\left.\mathrm{PyZn}\right)$ can be observed along the leached layer. In micrographs of the coating formed from paint T3-EMPAniESPy (Figure 10b), the coating behaved in a manner similar to that observed for paint T1-EMPy. In addition to displaying a porous matrix formed by the resin, indicating the leaching of pigments and fillers to interface with water, there is also a small amount of $\mathrm{Cu}_{2} \mathrm{O}$ grains in the innermost part of the film.

\section{Conclusions}

Although having an excellent performance in salt spray testing, the use of bicomponent epoxy resin, as a vehicle in the paints' formulation, was not suitable for use in the in-situ immersion test in marine environment (Imbé / Brazil). The performance against marine fouling, more specifically the adhesion of barnacles or Balanus, was unsatisfactory compared with the commercial paint used for reference. Moreover, the resin reticulation agent, based on polyamidoamine, seems to undope the PAni owing to its basic character. Therefore, a monocomponent epoxy resin was used, which did not require a reticulation agent, thus maintaining the PAni in desired form.

The performance in salt spray testing, of coatings containing monocomponent epoxy resin as a vehicle, was lower than that presented by the bicomponent epoxy resin, which is the reason why it does not seem appropriate for the purpose of corrosion protection, but performed satisfactorily as an antifouling coating.

SEM micrographs of the coatings, before and after immersion in-situ test, showed that the presence of active molecules on the surface of the coating depends on their diffusion along the thickness of the coating, which appears to be facilitated by the presence of PAni and SPAN.

The separate addition of PAni or co-biocide PyZn produces no change in the results of copper leaching. However, the combination of conducting polymer (PAni-EB or PAni-ES) with PyZn increases the release of pigment, probably as a result of the different distribution of pigments and charge in the film, and different interactions between molecules of biocide with the conductive polymer, since the resin used in the processing of paints was the same for all formulations.

Antifouling tests performed in marine environment, both in Brazil and in France, showed that with the addition of conductive form of PAni (PAni-ES, PAni/DBSA or SPAN) 
in the paint containing only cuprous oxide, the antifouling performance improved, when compared with coatings containing only $\mathrm{Cu}_{2} \mathrm{O}$. The combination of conducting polymers with co-biocide PyZn produces coatings as good as, or even better than coatings obtained with commercial paints. Therefore, it can be said that doped polyaniline (PAni-ES and PAni/DBSA) and its sulphonated form (SPAN) can be used as additives in antifouling paints, improving the efficiency of antifouling coatings, reducing the amount

\section{References}

1. Champ MA, and Lowenstein FL. TBT: The dilemma of antifouling paints. Ocean Fall. 1987; 30:69-77.

2. Myers JH, Gunthorpe L, Allinson G and Duda S. Effects of antifouling biocides to the germination and growth of the marine macroalga, Hormosira banksii (Turner) Desicaine. Marine Pollution Bulletin. 2006; 52(9):1048-1055. http:// dx.doi.org/10.1016/j.marpolbul.2006.01.010. PMid:16540127.

3. Yebra DM, Kiil S and Dam-Johansen K. Antifouling technology: past, present and future steps towards efficient and environmentally friendly antifouling coatings. Progress in Organic Coatings. 2004; 50(2):75-104. http://dx.doi.org/10.1016/j.porgcoat.2003.06.001.

4. Fay F, Linossier I, Langlois V, Haras D and Vallee-Rehel K. SEM and EDX analysis: Two powerful techniques for the study of antifouling paints. Progress in Organic Coatings. 2005; 54(3):216-223. http://dx.doi.org/10.1016/j.porgcoat.2005.05.005.

5. Song YC, Woo JH, Park SH and Kim IS. A study on the treatment of antifouling paint waste from shipyard. Marine Pollution Bulletin. 2005; 51(8-12):1048-1053. http://dx.doi. org/10.1016/j.marpolbul.2005.02.017. PMid:16291205.

6. Almeida E, Diamantino TC and Sousa O. Marine paints: the particular case of antifouling paints. Progress in Organic Coatings. 2007; 59(1):2-20. http://dx.doi.org/10.1016/j. porgcoat.2007.01.017.

7. Senda T. International trends in regulatory aspects. In: Arai T and Harino H., editors. Ecotoxicology of antifouling biocides. Tokyo: Springer; 2009. p. 23-38.

8. Oikonomou EK, Iatridi Z, Moschakou M, Damigos P, Bokias G and Kallitsis JK. Development of Cu2+- and/or phosphoniumbased polymeric biocidal materials and their potential application in antifouling paints. Progress in Organic Coatings. 2012; 75(3):190-199. http://dx.doi.org/10.1016/j.porgcoat.2012.04.019.

9. Bellotti N, Deyá C, del Amo B and Romagnoli R. Antifouling Paints with Zinc "Tannate". Industrial \& Engineering Chemistry Research. 2010; 49(7):3386-3390. http://dx.doi.org/10.1021/ ie 9010518 .

10. Camail M, Humbert M, Margaillan A, Riondel A and Vernet JL. New acrylic titanium polymers: 1 . Synthesis and characterisation of new titanium trialkoxide methacrylate monomers prepared via the esterification of methacrylic acid by titanium tetraalkoxides. Polymer. 1998; 39(25):6525-6531. http://dx.doi.org/10.1016/ S0032-3861(98)00145-1.

11. Voulvoulis N, Scrimshaw MD and Lester JN. Comparative environmental assessment of biocides used in antifouling paints. Chemosphere. 2002; 47(7):789-795. http://dx.doi.org/10.1016/ S0045-6535(01)00336-8. PMid:12079074.

12. Meneguzzi A, Ferreira CA, Pham MC, Delamar M and Lacaze PC.Electrochemical synthesis and characterization of poly(5amino-1-naphthol) on mild steel electrodes for corrosion of $\mathrm{Cu}_{2} \mathrm{O}$ used in the formulations and hence its release to marine environment.

\section{Acknowledgements}

The authors would like to thank $\mathrm{CNPq}$ for doctoral fellowship and financial support (Edital Universal 2004 and 2006), and CAPES (International Cooperation CAPESCofecub).

protection. Electrochimica Acta. 1999; 44:2149. http://dx.doi. org/10.1016/S0013-4686(98)00323-5.

13. Kinlen PJ, Silverman DC and Jefreys CR. Corrosion protection using polyanujne coating formulations. Synthetic Metals. 1997; 85(1-3):1327-1332. http://dx.doi.org/10.1016/S03796779(97)80257-3.

14. Meneguzzi A, Pham MC, Lacroix JC, Piro B, Adenier A, Ferreira $\mathrm{CA}$, et al. Electroactive Poly(aromatic amine) Films for Iron Protection in Sulfate Medium. Journal of the Electrochemical Society. 2001; 148(4):B121. http://dx.doi.org/10.1149/1.1354613.

15. Bernard MC, Hugot-Le Goff A, Joiret S, Dinh NN and Toan NN. Polyaniline layer for iron protection in sulfate medium. Journal of the Electrochemical Society. 1999; 146(3):995. http://dx.doi.org/10.1149/1.1391711.

16. Lenz DM, Delamar M and Ferreira CA. Application of polypyrrole/TiO2 composite films as corrosion protection of mild steel. Journal of Electroanalytical Chemistry. 2003; 540:35-44. http://dx.doi.org/10.1016/S0022-0728(02)01272-X.

17. Lenz DM, Delamar M and Ferreira CA. Improvement of the anticorrosion properties of polypyrrole by zinc phosphate pigment incorporation. Progress in Organic Coatings. 2007; 58(1):64-69. http://dx.doi.org/10.1016/j.porgcoat.2006.12.002.

18. Wang X-H, Li J, Zhang J-Y, Sun Z-C, Yu L, Jing X-B, et al. Polyaniline as marine antifouling and corrosion-prevention agent. Synthetic Metals. 1999; 102(1-3):1377-1380. http:// dx.doi.org/10.1016/S0379-6779(98)00384-1.

19. Ferreira CA and Baldissera AF. Tinta anti-incrustante, processo de produção da mesma, método de revestimento de superficies, $e$, superficies revestidas por tinta anti-incrustante. Patent PI1102440-2; 2011.

20. MacDiarmid AG and Epstein AJ. Polyanilines: a novel class of conducting polymers. Faraday Discussions of the Chemical Society. 1989; 88:317. http://dx.doi.org/10.1039/dc9898800317.

21. Baldissera AF. Development of unconventional antifouling paint to protect ships and steel structures [Thesis]. Porto Alegre: Engineering School, Federal University of Rio Grande do Sul; 2008.

22. Smits FM. Measurement of sheet resistivities with the four-point probe. The Bell System Technical Journal. 1958; 37(3):711-718.

23. American Society for Testing and Materials - ASTM. D335997: standard test methods for measuring adesion by tape test. West Conshohocken; 1997.

24. International Organization for Standardization - ISO. ISO 46283: paints and varnishes: evaluation of degradation of coatings: designation of quantity and size of defects, and of intensity of uniform changes in appearance. part 3: assessment of degree of rusting. Geneva; 2003. 
25. American Society for Testing and Materials - ASTM. D71402: standard test method for evaluating degree of blistering of paints. West Conshohocken; 2002.

26. Associação Brasileira de Normas Técnicas - ABNT. NBR MB 787-74: execução de ensaios de névoa salina de superfícies pintadas ou com revestimentos similares: migração subcutânea. West Conshohocken; 1974.

27. American Society for Testing and Materials - ASTM. D644205: standard test method for detemination of copper release rate from antifouling coatings in substitute ocean water. West Conshohocken; 2005.

28. Baldissera AF and Ferreira CA. Coatings based on electronic conducting polymers for corrosion protection of metals.
Progress in Organic Coatings. 2012; 75(3):241-247. http:// dx.doi.org/10.1016/j.porgcoat.2012.05.004.

29. Zaton M, Vinn O and Tomescu AMF. Invasion of freshwater and variable marginal marine habitats by microconchid tubeworms: an evolutionary perspective. Geobios. 2012; 45(6):603-610. http://dx.doi.org/10.1016/j.geobios.2011.12.003.

30. Campos TLA, Kersting DF and Ferreira CA. Chemical synthesis of polyaniline using sulphanilic acid as dopant agent into the reactional medium. Surface and Coatings Technology. 1999; 122(1):3-5. http://dx.doi.org/10.1016/S0257-8972(99)00399-0.

31. Thouvenin M, Peron J-J, Charreteur C, Guerin P, Langlois J-Y and Vallee-Rehel K. A study of the biocide release from antifouling paints. Progress in Organic Coatings. 2002; 44(2):75-83. http:// dx.doi.org/10.1016/S0300-9440(01)00246-6. 